\title{
Influence of temperature and impact velocity on the impact response of jute/UP composites
}

\author{
H. N. Dhakal ${ }^{* a}$, V. Arumugam ${ }^{\text {b }}$, A. Aswinraj ${ }^{\text {b }}$ C. Santulli ${ }^{\text {c }}$, Z. Y. Zhang a A. Lopez-Arraiza ${ }^{\text {d }}$ \\ ${ }^{a}$ Advanced Polymer and Composites (APC) Research Group \\ School of Engineering \\ University of Portsmouth, Anglesea Road, Anglesea Building, Portsmouth, Hampshire, PO1 \\ 3DJ, U.K. \\ ${ }^{\mathrm{b}}$ Department of Aerospace Engineering, MIT Campus, Chromepet, Anna University, Chennai-44 \\ Tamilnadu, India. \\ ${ }^{c}$ Università degli Studi di Camerino, School of Architecture and Design, viale della \\ Rimembranza, 63100 Ascoli Piceno, Italy. \\ ${ }^{\mathrm{d}}$ University of the Basque Country (UPV/EHU), Higher Tech. School of Nautical and Marine \\ Machines, Maria Diaz de Haro, 68, E48920 Portugalete-Bizkaia, Spain.
}

\begin{abstract}
During the last decade, interest in using natural fibre reinforced composites has increased due to their good specific mechanical properties. The results of an experimental study of the influence of temperature and impact velocity on the low velocity impact response of jute fiber reinforced unsaturated polyester (UP) composite laminates is presented. A series of low velocity impact tests were performed using an instrumented falling weight test system at three different temperatures $\left(30,50\right.$ and $\left.75^{\circ} \mathrm{C}\right)$ and two impact velocities $(1.5$ and $2 \mathrm{~m} / \mathrm{s})$. The results indicate that jute/UP composites were able to withstand higher loads when tested at $30^{\circ} \mathrm{C}$. The composites were subsequently subjected to three-point bending tests in order to investigate the flexural strength after impact (FAI) and it was found that FAI significantly decreased with increase in test temperature. Impact damage characterised by AE revealed delamination as a major failure mode.
\end{abstract}

Keywords: Polymer-matrix composites (PMCs), Natural fibre, Impact behaviour, Delamination.

* Corresponding author. Tel: + 44 (0) 239284 2582; fax: + 44 (0) 2392842351.

E-mail: hom.dhakal@port.ac.uk (H. N. Dhakal) 


\section{INTRODUCTION}

A growing environmental awareness across the world has aroused interest in research and development of environmentally friendly and sustainable materials [1-3]. As the cost of non-renewable sources of material becomes more expensive, natural fibres can be a viable alternative as reinforcement for composite materials [4, 5]. The use of natural fibres for the reinforcement of polymeric composite materials has received increasing attention by both academia and industry because of their availability, lower density, much higher specific strength and not causing irritation when handled compared to conventional glass fibres [6, 7]. In addition, the production of these fibres require less energy than conventional fibres Although bast fibre (hemp, flax and jute) composites have been successfully used for nonstructural, semi-structural and low cost applications in recent years, there are still significant barriers for structural applications of these composites [8, 9].

The use of composite materials in structural components has increased significantly in recent years by offering potential benefits to the aerospace, automotive and marine industry. However, composite laminates used in these various applications are susceptible to delamination, from a wide variety of sources including low velocity impact damage. Impact actions induced by flying solid objects such as runway debris, hand tools fall down on composites have attracted a great deal of research interest in the areas of crashworthiness of vehicles and impact damage assessment of composite materials. Low velocity impact damage causes delamination which can reduce the structural integrity of the composite materials significantly. An understanding the effect of damage and post impact damage due to low velocity impact is an important subject to be investigated in natural fiber reinforced composites [10, 11]. However, the impact resistance of a composite material is always difficult to determine due to other factors such as delamination at the interface, fiber breakage, matrix cracking and fiber pull out [12-14].

Acoustic emission (AE) is widely used in industry to inspect and monitor the condition of composite materials. AE is a passive technique that monitors a structure while under loading. An alternative approach to evaluate impact tolerance of a composite laminate is the assessment of its residual post-impact properties [15-18]. This can be carried out using real time monitoring techniques, such as acoustic emission, which cannot be easily applied directly during 
impact loading due to short timeframe involved, , unless acoustic emission sensors are embedded in the laminate, which may not be very practical on plant fibre composites [19].

There are many reported works on the effect of temperature on the impact damage response of conventional fibre reinforced composites. Kang et al. [20] evaluated the effect of temperature on impact damage resistance of glass/epoxy laminates at temperature ranging from $40^{\circ} \mathrm{C}$ to $+80^{\circ} \mathrm{C}$. They suggest that temperature had a little effect on the impact response of composite laminates. The work carried out by Erickson et al. [21] on sandwich structures showed that temperature can have a significant effect on impact damage characteristics. Daiyan et al. [22] investigated the effects of plate thickness, impact velocity and temperature on low velocity impact response of injection moulded polypropylene plates. Similarly, Yang and Cantwell [23] carried out low velocity impact testing [23] on glass/epoxy composite at temperatures ranging between 23 and $90^{\circ} \mathrm{C}$. Their work suggests that temperature can play a significant role on impact damage threshold. Boominathan et al [24] conducted low velocity impacts on unidirectional and symmetric cross carbon/epoxy specimens at $1.5 \mathrm{~m} / \mathrm{s}$ under ambient and elevated temperatures $\left(50^{\circ} \mathrm{C}, 75^{\circ} \mathrm{C}\right.$ and $\left.90^{\circ} \mathrm{C}\right)$. Specimens of both categories showed an increase in residual flexural strength, and resistance to impact was observed up to $75^{\circ} \mathrm{C}$, while an opposite trend was noticed closer to the glass transition temperature of the resin. The majority of the reported works suggest that temperature can have significant influence on energy absorption and damage mechanisms. However, not much has been reported on the relationship between the impact response of natural fibre composites and temperature.

A.U. Ude et al [25] investigated the impact damage in reinforced woven natural silk (NS)/epoxycomposite such as (a) NS/Epoxy/Honeycomb; (b) NS/Epoxy/Foam; (c) NS/Epoxy/Coremat; (d) NS/Epoxy. Drop weight impact tests were carried out on the composite panels at impact energies levels of $32 \mathrm{~J}, 48 \mathrm{~J}$ and $64 \mathrm{~J}$. At each energy level, the different failure modes were studied for each type of composite specimen. From the impact results, NS/Epoxy/Foam specimen exhibited higher energy attenuation capability than the other configurations. It was reported that NS/Epoxy/Coremat exhibited higher load bearing capability than other sandwich types. Wiphawee Nuthong et al [26] studied the impact response of polylactic acid (PLA) which is recognised for its biocompatible and biodegradable properties. In 
order to reduce the brittle nature of PLA and improve strength, natural fibres such as bamboo fiber, vetiver grass fiber and coconut fiber were used as alternative reinforcements in PLA composites. The maximum reduction in impact strength was 23.8, 27.3 and $56.2 \%$ for bamboo fiber/PLA, vetiver grass fiber/PLA and coconut fiber/PLA composites, respectively. After treatment, the natural fibre reinforced PLA showed improved impact resistance compared to untreated composites. Yupaporn Ruksakulpiwat et al [27] conducted an impact study on vetiver grass polypropylene composite by using natural rubber and Ethylene Propylene Diene Monomer (EPDM) rubber. The effect of rubber additives on the different mechanical properties of natural fiber composites was studied and increase in the impact strength and percentage elongation was observed for $20 \%$ wt of rubber, but other properties such as tensile strength and Young's modulus were reduced.

Paul Wambua et al [28] investigated the effect of high velocity impact study on flax, hemp and jute fabric reinforced polypropylene composites. The investigation was also extended to mild steel plates used as facing and backing for the natural composites. Energy absorption for flax composites was better than hemp and jute composites. It was found that the ballistic properties of the hemp composites increased when a mild steel plate was used as facing and backing.

Although the above mentioned works gives us a better insight on the impact characteristics of natural fibre composites at different levels of application, varying from sandwich structures to high velocity impacts, there is no extensive study on behaviour of natural fibre composites subjected to impact at different temperatures. Hence, this study would be a next step forward in addressing the implementation of natural fibres in real time environments.

Acoustic emission (AE) is a promising potential non-destructive evaluation (NDE) technique for fibre composites [29]. Acoustic emission is generated by microscopic failure events that occur when a structure is loaded. Generally encountered failure modes that are detected using $\mathrm{AE}$ in a composite structure are fibre fracture, matrix cracking, fibre-matrix interfacial debonding, and delamination. When these failure events occur, transient, elastic stress waves are generated which can be detected by piezoelectric sensors attached to composite structure using suitable couplants. Many researchers have attempted to identify the failure modes using two different approaches, namely parametric based approach and signal based approach 
[30,31]. Classification of failure modes based on the frequency content of AE signals obtained from different ply orientations have been investigated by Ramirez-Jimenez et al [32] and Arumugam et al. [33]. Both of their studies report fibre failure in the high frequency range and matrix cracking is identified in the low frequency range, while delaminations have a frequency range between fibre failure and matrix cracking. Boominathan et al. [24] investigated the effect

of temperature, not only on impact of carbon epoxy specimens, but also on peak frequency versus time plots obtained from acoustic emission data acquired during post impact flexural tests.

Jute is a fibrous material produced from the stem of Corchorus olitorius and is composed of $60-65 \%$ cellulose, $20-22 \%$ hemicellulose, $10-14 \%$ lignin and approximately $2 \%$ protein. In this study, we aim at investigating the influence of temperatures and impact velocities on the low-velocity impact response and post-impact flexural strength of jute fiber reinforced unsaturated polyester composite. The jute/UP composites were impacted at two different velocities $\left(1.5\right.$ and $2 \mathrm{~m} / \mathrm{s}$ ) and three different temperatures (ambient temperature of $30^{\circ} \mathrm{C}$ and elevated temperatures of 50 and $75^{\circ} \mathrm{C}$ ) subjected to impact damage leading only to non penetrating failures. The values of temperatures and the impact velocities were chosen because they best resembled conditions encountered in practical low velocity impact cases. The impact response of the composites is compared in terms of peak impact force, energy absorbed and post impact three-point bending flexural strength. The information obtained from this study can be ustilised in designing lightweight structures and products in automotive, aerospace and marine applications.

\section{EXPERIMENTAL}

\subsection{Materials}

Low viscosity unsaturated polyester (UP) with the commercial name Enydyne I 68835 supplied by Cray Valley was used as matrix in the preparation of the composite laminates. The matrix material was mixed with curing catalyst, methyl ethyl ketone peroxide (MEKP), at a concentration of $1.5 \mathrm{wt} . \%$ as recommended by the manufacturer. The jute fibre reinforcement was balanced fabric $0 / 90$ of $300 \mathrm{gsm}$.

\subsection{Composite preparations}


The composite laminates were manufactured by hand lay-up and vacuum bagging process in plate of $6 \mathrm{~mm}$ thickness. The fibre weight fraction was $33 \%$ and the void content was 5\%. The contents were calculated according to ASTM D2734-94 for conducting burn off test which results in complete oxidation of resin thereby jute fibre volume could be determined.

\subsection{Drop weight impact test}

Non-penetrating low-velocity impact tests were performed on a Fractovis Plus drop weight test machine with an impactor of mass of $1.926 \mathrm{~kg}$ with a hemispherical steel tup diameter of $20.7 \mathrm{~mm}$, as depicted in Figure 1. The clamping system has an outer diameter of 120 $\mathrm{mm}$ and inner diameter of $76 \mathrm{~mm}$. Temperature control (ranging from 30 to $75{ }^{\circ} \mathrm{C}$ ) was achieved by an air circulated environmental chamber attached to the impact test system in which the specimens were placed and clamped along their outer border. The drop heights were adjusted to generate incident impact energies of $2.166 \mathrm{~J}$ for $1.5 \mathrm{~m} / \mathrm{s}$ and $3.852 \mathrm{~J}$ for $2 \mathrm{~m} / \mathrm{s}$ impact velocity, sufficient to initiate minimal visible damage (non-penetrating) on the square specimens of side length $70 \mathrm{~mm}$ with thickness of $6 \mathrm{~mm}$. A catcher mechanism was activated to avoid the multiple impacts on the specimens. The impact test history, including impact force, impact time, deformation and energy absorbed were obtained by the instrumented tup.

\subsection{Post impact damage characterisation}

\subsubsection{Post impact flexural testing}

Upon completion of impact testing, the samples were subjected to 3-point bending (flexural) testing in an effort to determine the damage effects of impact on residual strengths of jute/UP composites. For this, the impacted plates were subjected to post impact three point bending tests in accordance with ISO 978 in a Tinus Olsen H100KU universal testing machine using a support span of $50 \mathrm{~mm}$ and a cross head speed of $0.25 \mathrm{~mm} / \mathrm{min}$ at room temperature (Figure 2). Four specimens were tested for each temperature, including non-impacted specimens, which served as reference materials. The flexural test method was chosen as in this method specimens fail in either compression at the rear of the impacted face or tension at the front face, where compression is the more critical failure mode after an impact event.

\subsection{Accoustic emission monitoring}

Following impact, post impact damage was analysed with the application of an 8 channel AE system supplied by Physical Acoustics Corporation (PAC). The sampling rate and pre- 
amplification were kept as 1 MSPS and $40 \mathrm{~dB}$, respectively. Preamplifiers having a bandwidth of $10 \mathrm{kHz}-2 \mathrm{MHz}$ are used. AE activities were sensed using a wide band WD piezoelectric sensor, filtering out frequencies exceeding $900 \mathrm{kHz}$, and using a threshold of $45 \mathrm{~dB}$. High vacuum silicon grease was used as a couplant. The amplitude distribution covers the range $0-100 \mathrm{~dB}(0$ $\mathrm{dB}$ corresponds to $1 \mu \mathrm{V}$ at the transducer output). After mounting two transducers on the sample at a mutual distance of $40 \mathrm{~mm}$ between them, so that they were both at the same distance from the centre of the specimen length, a pencil lead break procedure was used to generate repeatable AE signals for the calibration of each sensor. Velocity and attenuation studies were performed on the laminates. The average wave velocity in the material was found to be $3000 \mathrm{~m} / \mathrm{s}$. The PreTrigger value and the Hits length value are estimated as $26 \mu \mathrm{s}$ and $32 \mu \mathrm{s}$. The timing parameters in the hardware settings are calculated and are as follows: peak definition time (PDT) $=13 \mu \mathrm{s}$, hit definition time $(\mathrm{HDT})=160 \mu \mathrm{s}$, hit lockout time $(\mathrm{HLT})=300 \mu \mathrm{s}$. The HDT was calculated from trial and error. Proper setting of the HDT ensures that each signal from the structure is reported as one signal only.

\subsection{Dynamic mechanical analysis (DMA)}

DMA was used to gather elastic modulus, loss modulus and damping coefficient of the composite materials as a function of temperature. In DMA, the glass transition temperature $(\mathrm{Tg})$ can also be determined accurately from the elastic and loss modulus response as a function of temperature. In this work, the correct elevated temperature was determined by evaluating the correct glass transition temperature. In order to identify the Tg, the jute/UP specimen was tested by DMA using a TA instrument Q800 in 3-point bending mode. The test coupons were cut down to $60 \times 5 \times 4 \mathrm{~mm}$ using a diamond wheel saw. The test coupon was heated from $20{ }^{\circ} \mathrm{C}$ to $100{ }^{\circ} \mathrm{C}$ at $1^{\circ} \mathrm{C} /$ min and the frequency was kept as $1 \mathrm{~Hz}$.

\section{Results and discussion}

\subsection{Glass transition temperature, $\mathrm{Tg}$.}

Figure 3 illustrates DMA test result for jute/UP which shows a glass transition temperature $\mathrm{Tg}$ of approximately $71{ }^{\circ} \mathrm{C}$. Based on this obtained $\mathrm{Tg}$ value, the maximum elevated temperature for impact testing of jute/UP specimens was selected as $75{ }^{\circ} \mathrm{C}$, close to its $\mathrm{Tg}$. The curves also show that storage modulus decreases from $30^{\circ} \mathrm{C}$, that is to say, the composite begins the transition from viscoelastic to viscoplastic behaviour. 


\subsection{Influence of temperature and impact velocity on the impact performance}

Figures 4 (a), (b) and (c) illustrate the absorbed energy, peak force and deformation Vs impact temperatures for 1.5 and $2 \mathrm{~m} / \mathrm{s}$ impact velocity levels. From Figure 4 (a), it could be observed that absorbed energy is highest in the case of specimens subjected to impact at $75^{\circ} \mathrm{C}$ at both impact velocities. As the temperature increases the absorbed energy tends to increase which can be explained as a result of viscoplastic behaviour, except in the case of specimens subjected to $1.5 \mathrm{~m} / \mathrm{s}$ impact velocity where the absorbed energy at $50^{\circ} \mathrm{C}$ is slightly less than ambient specimens although the decrease is. not significant

From Figure 4 (b), it can be seen that impact force is governed by the temperature which combines the effect of contact velocity, geometrical properties of the specimen and the projectile. In Figure 4(b), the highest contact force is obtained for specimens tested at $30^{\circ} \mathrm{C}$ for velocities of 1.5 and $2 \mathrm{~m} / \mathrm{s}$. As the impact temperature increases the peak contact force decreases for both impact velocities. Figure 4(c) shows the deformation Vs time plot for specimens subjected to 1.5 and $2 \mathrm{~m} / \mathrm{s}$ impact velocities. The deformation kept increasing as the impact temperature increases. The maximum deformation was observed for specimens subjected to impact at $75^{\circ} \mathrm{C}$.

Figures 5 (a) and (b) show the contact force Vs deformation for the specimens impacted at velocities of 1.5 and $2 \mathrm{~m} / \mathrm{s}$. The decrease in slope of the curve until peak contact force and the ratio of large deformation to the impact force indicates a drop in the stiffness of the jute/UP composites. It is interesting to note that for all temperatures in the case of $1.5 \mathrm{~m} / \mathrm{s} \mathrm{impact}$ velocity; the drop in impact force is not sudden, which is an indication of stable delimitation size growth as an indication of slow drop in the stiffness of the composites. The decrease in impact force with increasing impact temperature is due to changes in the interfacial strength (weaker as the temperature increases) which indicates that the performance of the composites tested at $30^{\circ} \mathrm{C}$ and $50^{\circ} \mathrm{C}$ is better than when tested at an elevated temperature. The contact force Vs deformation curves for $2 \mathrm{~m} / \mathrm{s}$ is shown in Figure 5 (b) and a similar trend is observed whereby the impact force of specimens impacted at $30^{\circ} \mathrm{C}$ and $50^{\circ} \mathrm{C}$ is higher than that of specimens impacted at elevated temperature of $75^{\circ} \mathrm{C}$. As the temperature increases, the contact force decreases and maximum deformation increases for both $1.5 \mathrm{~m} / \mathrm{s}$ and $2 \mathrm{~m} / \mathrm{s}$ impact specimens. The contact force and deformation depends very much on the fibre/matrix interface. Therefore, the specimens 
impacted at lower temperatures shows higher stiffness due to their better fibre matrix interace compared to specimens impacted at the elevated temperature. The elevated temperature can have significant effects on the subsequent performance of composite structure under low velocity impact events [30].

\subsection{Impact damage evaluation}

Figure 6 illustrates the magnitude of indentation observed by visual inspection for jute/UP specimens impacted at the velocity of $1.5 \mathrm{~m} / \mathrm{s}$. As can be seen, there are minor matrix cracks on the impacted front face (compression) and fibre straining on the rear face of the specimens showing increased damaged area. The damage areas on the front faces of the impacted specimens are limited to the diameter of the impactor. Damage at the rear face (tension) of the specimen is more visible for all the specimens. At higher temperatures, especially in the case of specimens tested at $75^{\circ} \mathrm{C}$, the damage pattern appears to be more visible and extended. This trend suggests that the the damage area and delamination increases as the test temperature is increased.

A similar trend is observed for jute/UP specimens impacted at $2 \mathrm{~m} / \mathrm{s}$ with different temperature as shown in Figure 7. The front and the rear faces of the specimens impacted at 30 and $50{ }^{\circ} \mathrm{C}$ show that, as the temperature increase, the damage area also increases. Damage at the rear face of the specimen is more visible for all the specimens. As was observed for the specimens impacted at the velocity of $1.5 \mathrm{~m} / \mathrm{s}$, at higher temperatures, especially in the case of specimens tested at $75^{\circ} \mathrm{C}$, the impacted front face shows damage in the form of fibre shear, and matrix fracture was limited to the diameter of the impact tup, as observed for $1.5 \mathrm{~m} / \mathrm{s}$ velocity, and the rear face damage pattern shows larger damage area. It is worth noting that there is no significant change in damage areas between impact velocities of 1.5 and $2 \mathrm{~m} / \mathrm{s}$.

For both impact velocity levels, the delamination patterns seem circular with local indentation on the front face and cross-shaped on the rear. It is interesting to note that at the elevated temperature of $75^{\circ} \mathrm{C}$, the visual damage area on the rear face spreads as a result of greater delamination or higher elongation. It is proven that temperature significantly influnces the impact damage of jute/UP laminates. However, the damage patterns revealed by the AE testing confirm that the delamination areas increase as the temperature is increased. The impact 
induced in these somposites was low energy impact and, as a result, the main damage pattern for specimens impacted at both velocity levels is delamination with small matrix fracture, debonding and fibre breakage.

\subsection{Evaluation of flexural strength after impact (FAI)}

Figure 8 illustrates the flexural strength after impact (FAI) of samples under three point bending test in comparison to the the results from the non-impacted samples. It is evident from the figure that the flexural strength after impact decreases with the increase in impact temperature. The minimum reduction in flexural strength is observed in the case of specimens subjected to the impact velocity of $1.5 \mathrm{~m} / \mathrm{s}$ at ambient conditions. There is a sudden increase in percentage reduction in flexural strength at $50^{\circ} \mathrm{C}$ when compared with ambient. In the case of specimens subject to impact at the velocity of $2 \mathrm{~m} / \mathrm{s}$, there is no appreciable change in percentage reduction in flexural strength compared to $1.5 \mathrm{~m} / \mathrm{s}$. For specimens impacted at $75^{\circ} \mathrm{C}$, the flexural strength after impact (FAI) is slightly lower than that of specimens impacted at $30^{\circ} \mathrm{C}$ and $50^{\circ} \mathrm{C}$ in both cases. This is related to an decrease in interfacial strength due to increase in test temperature.

\subsection{Characterisation of failure modes by acoustic emission}

Frequency analysis was performed on the AE data obtained during the flexural testing of jute specimens subjected to impact at ambient $\left(30^{\circ} \mathrm{C}\right)$ and elevated temperature $\left(50^{\circ} \mathrm{C}\right.$ and $\left.75^{\circ} \mathrm{C}\right)$. Frequency analysis is a promising technique to discriminate the failure modes occurring in the composite structures (Figure 9). Each failure mode generates an AE signal, which is related to the amount of strain energy released. Peak frequency and cumulative counts Vs time plots were useful to segregate the frequency ranges of different damage mechanisms such as matrix failure, debonding, delamination and fibre failure in different specimens. The ranges of frequency content pertaining to the different failure modes for jute/UP coupons subjected to flexural test with AE monitoring are carried out using the frequency analysis. Matrix failure $(80-170 \mathrm{kHz})$ is attributed as low freuency failure mode, and fiber failure is associated with high frequency failure range $(300-350 \mathrm{kHz})$. Delamination $(200-260 \mathrm{kHz})$ and debonding $(270-300 \mathrm{KHz})$ are mid frequency range failures which are usually sorted considering amplitude and duration parameters. Delamination failure mode is usually associated with medium to long duration and 
medium to high amplitude, whereas debonding is associated with short to medium duration and low to medium amplitude. [33, 24, 37]

Figures 9 (a), (b), (c) \& (d) show the peak frequency and cumulative count Vs time for non impacted and specimens subjected to impact at ambient $\left(30^{\circ} \mathrm{C}\right)$ and elevated temperatures $\left(50^{\circ} \mathrm{C}\right.$ and $\left.75^{\circ} \mathrm{C}\right)$. Hits corresponding to different failure modes were present from the beginning of the test for specimens subjected to impact, whereas no considerable AE activity was present until $180 \mathrm{~s}$ in the case of non-impact specimen.

Figure 10 shows the percentage of hits (\%) for different failure modes for $2 \mathrm{~m} / \mathrm{s}$. Considering the matrix cracking failure mode, as the impact temperature increases, the percentage of hits corresponding to $80-170 \mathrm{kHz}$ peak frequency follows a decreasing trend compred to ambient condition impact. This could be possibly due to softening effect of matrix as the temperature increases. Delamination is the predominant failure mode in deciding the post impact flexural strength. As the impact temperature increases to $75^{\circ} \mathrm{C}$, the percentage of hits corresponding to delmaination shows an increase compared to ambient and $50^{\circ} \mathrm{C}$. This increment in delamination percentage with respect to temperature is reflected in the decresing trend in residual flexural strength as illustrated in Figure 8. In the case of specimens subjected to impact at ambient condition, the percentage of hits corresponding to fiber failure was higher when compared to matrix failure and debonding. But it did not influence the residual strength like the other damage modes such as delamination and matrix cracking. Debonding failure mode had a insignificant percentage of hits when compared to the other failure modes.

The percentage of hits corresponding to matrix failure was almost same in the case of ambient impact specimens and $50^{\circ} \mathrm{C}$ specimens (19.3\% for ambient and $19.5 \%$ for $\left.50^{\circ} \mathrm{C}\right)$ but there was an increase in the percentage of hits corresponding to the matrix failure (approximately $175 \%$ increase) when compared to non impacted specimens. Moreover, at $75^{\circ} \mathrm{C}$, when the impact temperature is higher than the $\mathrm{T}_{\mathrm{g}}$, the softening of matrix phenomenon is confirmed by the decrease in the percentage of hits corresponding to matrix . The percentage of hits corresponding to delamination followed a decreasing trend until $50^{\circ} \mathrm{C}$, it was $63.9 \%$ for non-impact specimen, $61.4 \%$ for ambient, $43 \%$ for $50{ }^{\circ} \mathrm{C}$, but after the $\mathrm{T}_{\mathrm{g}}$ temperature there was a sudden increase in the percentage of hits corresponding to delamination. This could be possibly attributed to the 
weak interface between the plies after $\mathrm{T}_{\mathrm{g}}$ temperature. For all the cases, fiber failure showed a fluctuating trend, varying between $8 \%$ to $11 \%$.

A low velocity impact, failure sequence in composite laminate consists typically of four major failure modes namely matrix cracking, delamination, following matrix crack, fibre breakage and full penetration, once the projectile completely perforates the structure of the impacted specimen $[35,36]$. From Figure 10, it is clear that delamination was the predominant failure mode irrespective of the impact temperature and non impact condition during the flexural test. Some matrix cracking followed by debonding and fibre breakage is also evident.

\section{Conclusions}

The influence of temperature and impact velocity on the impact damage performance of jute fibre reinforced unsaturated polyester composite material has been investigated through non-penetration impact under low velocity impact testing. The results show that temperature and impact velocity have a major influence on the energy absorption and impact and post impact damage characteristics. The residual flexural strength was affected by the temperature of the impact test. At lower temperatures i.e. $30^{\circ} \mathrm{C}$ and $50^{\circ} \mathrm{C}$, the jute/ $\mathrm{UP}$ specimens retained the highest proportion of its initial strength compared to the specimens tested at $75^{\circ} \mathrm{C}$. The impact and post impact test results show that the predominant failure mode of jute/UP composites was delamination, irrespective of the impact temperature and velocity. 


\section{References}

[1] C. Hill, M. Hughes, Natural fibre reinforced composites: opportunities and challenges, Journal of Biobased Materials and Bioenergy 4 (2) (2010)148-158.

[2] P. Wambua, J. Ivens, I. Verpoest, Natural fibres: can they replace glass in fibre reinforced plastics?, Composites Science and Technology 63 (9) (2003) 1259-1264.

[3] H.N. Dhakal, Z.Y. Zhang, M.O.W. Richardson, Effect of water absorption on the mechanical properties of hemp fibre reinforced unsaturated polyester composites. Compos Sci Technol 67 (2007)1674-1683.

[4] O. Faruk, A.K. Bledzki, H.P. Fink, M. Sain, Biocomposites reinforced with natural fibres:2000-2010. Progress in Polymer Science 37 (2012)1552-1596.

[5] A.K. Bledzki, J. Gassan, Composites reinforced with cellulose base fibres. Prog Polym Sci 24 (1999) 221-74.

[6] S. Panthapulakkal, M.Sain, Injection-molded short hemp fiber/glass fiber-reinforced polypropylene hybrid composites. Mechanical, water absorption and thermal properties, Journal of Applied Polymer Science 103 (4), (2007) 2432-2441.

[7] H.N. Dhakal, Z.Y. Zhang, M.O.W. Richardson, Creep behaviour of hemp fibre reinforced unsaturated polyester composites. Journal of Biobased Materials and Bioenergy 3 (2009) 232237.

[8] T. Yuanjian, D.H. Isaac, Impact and fatigue behaviour of hemp fibre composites, Composites Science and Technology 67 (6) (2007) 3300-3307.

[9] Chen Y, Müller DH, Nießen K, Müssig J. Spunlaced flax/polypropylene nonwoven as auto interior material: mechanical performance, Journal of Industrial Textiles 38 (1), 2008, 69-86.

[10] H.N. Dhakal, Z.Y. Zhang, M.O.W. Richardson, O.A.Z. Errajhi, The low velocity impact response of non-woven hemp fibre reinforced unsaturated polyester composites. Compos Struct. 81 (2007) 559-67.

[11] I.M. De. Rosa, Igor, H.N. Dhakal, C. Santulli, F. Sarasini, Z.Y. Zhang, Post-Impact Static and Cyclic Flexural Characterisation of Hemp Fibre Reinforced Laminates. Composites Part B 43 (2012)1382-1396. 
[12] H.N. Dhakal, Z.Y. Zhang, N. Bennett,P.N.B Reis, Low-velocity impact response of nonwoven hemp fibre reinforced unsaturated polyester composites: Influence of impactor geometry and impact velocity. Composite Structures 94 (2012) 2756-2763.

[13] C. Santulli, A.P. Caruso, A comparative study on falling weight impact properties of jute/epoxy and hemp/epoxy laminates. Malaysian Polymer Journal 4 (2009) 19-29.

[14] W.J. Cantwell, Geometrical Effects in the Low Velocity Impact Response of GFRP, Compos Sci Technol. 67 (2007) 1900-1908.

[15] I.M. De Rosa, C. Santulli, F. Sarasini, M. Valente, Post-impact damage characterization of hybrid configurations of jute/glass polyester laminates using acoustic emission and IR thermography, Composites Science and Technology 69 (2009) 1142-1150.

[16] I.M. De Rosa, C. Santulli, F. Sarasini, M. Valente, Effect of loading-unloading cycles on impact-damaged jute/glass hybrid laminates, Polymer Composites 30 (12), 2009, 1879-1887.

[17] I.M. De Rosa, F. Sarasini, Use of PVDF as acoustic emission sensor for in situ monitoring of mechanical behaviour of glass/epoxy laminates, Polymer Testing 29 (2010)749-758.

[18] D. Kusic, T. Kek, J.M. Slabe R. Svecko, J. Grum, The impact of process parameters on test specimens and their correlation with AE signals captured during the injection moulding cycle. Polymer Testing 32 (2013) 583-593.

[19] C. Santulli, Post-impact flexural tests on jute/polyester laminates monitored by acoustic emission, Journal of Materials Science, 41 (4) (2006) 1255-1260.

[20] K.W. Kang, T.J. Chung, S.K. Koh, Temperature effect of low velocity impact resistance of glass/epoxy laminates. International Journal of Modern Physics B, 24 (2010) 2657.

[21] M.D. Erikson, A.R. Kallmeyer, K.G. Kellog, Effect of temperature on low velocity impact behaviour of composite sandwich panels. J Sandwich Structure Materials 7 (2005) 245-264.

[22] H. Daiyan, E. Andreassen, F. Grytten O.V. Lyngstad, T. Luksepp, H. Osnes, Low velocity impact response of injection-moulded polypropylene plates-part 1:Effects of plate thickness, impact velocity and temperature. Polymer Testing 29 (2010) 648-657.

[23] F.J. Yang, W.J. Cantwell, Impact damage initiation in composite materials. Composites Science and Technology 70 (2010) 336-342. 
[24] R. Boominathan, V. Arumugam, C. Santulli, A. Adhithya Plato Sidharth, R. Anand Sankar, B.T.N. Sridhar, Acoustic emission characterization of the temperature effect on falling weight impact damage in carbon/epoxy laminates. Composites: Part B, 56 (2014) 591-598.

[25] A.U. Ude, A.K. Ariffin, C.H. Azhari, Impact damage characteristics in reinforced woven natural silk/epoxy composite face-sheet and sandwich foam, coremat and honeycomb materials, International Journal of Impact Engineering, 58 (2013) 31-38

[26] W. Nuthong, P. Uawongsuwan, W. Pivsa-Art, H. Hamada, Impact Property of Flexible Epoxy Treated Natural Fiber Reinforced PLA Composites, Energy Procedia 34 (2013) 839-847

[27] Y. Ruksakulpiwat, J. Sridee, N. Suppakarn, W. Sutapun, Improvement of impact property of natural fiber-polypropylene composite by using natural rubber and EPDM rubber, Composites Part B: Engineering 40 (2009) 619-622.

[28] P. Wambua, B. Vangrimde, S. Lomov, I. Verpoest, The response of natural fibre composites to ballistic impact by fragment simulating projectiles, Composite Structures 77(2) ( 2007) 232240

[29] Fowler, E. Gray, "Development of an acoustic emission test for FRP equipment" Preprint 3583 from American Society of Civil Engineers Con ven tion and Exposition (Boston, MA, 1979)

[30] D. Valentin, P. Bonniau, A.R. Bunsell, Failure mechanism discrimination in carbon fibrereinforced epoxy composites, Composites, 14 (1983) 345-351.

[31] J.M. Berthelot, J. Rhazi, Acoustic emission in carbon fibre composites, Composites Science and Technology, 37 (1990) 411-428.

[32] C.R. Ramirez Jimenez, N. Papadakis, N. Reynolds, T.H.Gan, P. Purnell, M. Pharaoh, Identification of failure modes in glass/polypropylene composites by means of the primary frequency content of the acoustic emission event. Composites Science and Technology, 64 (2004) 1819-1827.

[33] V. Arumugam, S. Barath Kumar, C. Santulli, S.A. Joseph, Effect of fiber orientation in unidirectional glass epoxy laminate using acoustic emission monitoring. Acta Metallurgica Sinca (Engl Lett.) 24 (2011) 351-64. 
[34] V. Kostopoulos, A. Baltopoulos, P. Karapappas, A. Vavouliotis, A. Paipetis, Impact and after impact properties of carbon fibre reinforced composites enhanced with multi-wall carbon nanotubes. Composites Science and Technology70 (2010) 553-563.

[35] M.O.W. Richardson, M.J. Wisheart, Review of low velocity impact properties of composite materials. Composites Part A 27A (1996)1123-1131.

[36] L. Walker, M.S. Sohn, X.Z. Hu, Improving impact resistance of carbon fibre composites through interlaminar reinforcement. Composites Part A 33 (2002) 893-902.

[37] V.Arumugam, A. Adhithya Plato Sidharth, C. Santulli, Failure modes characterization of impacted carbon fibre reinforced plastics laminates under compression loading using acoustic emission. Journal of Composite Materials. Article in press. doi: 10.1177/0021998313509504

Table Captions

Table 1: Summary of failure mode characterization using DWT analysis of AE signals

\begin{tabular}{|c|c|c|c|c|}
\hline \multirow{2}{*}{ Materials } & $\begin{array}{c}\text { Decomposed } \\
\text { components }\end{array}$ & \% of Energy & $\begin{array}{c}\text { Frequency } \\
\text { range }(\mathrm{kHz})\end{array}$ & Types of Failure modes \\
\hline \multirow{2}{*}{ Hemp/Epoxy } & D3 & 22.68 & $200-290$ & Fiber failure \\
\cline { 2 - 5 } & D4 & 74.91 & $135-180$ & Fiber-Matrix interfacial debonding \\
\cline { 2 - 5 } & D5 & 2.41 & $70-130$ & Matrix cracking \\
\hline \multirow{2}{*}{$\begin{array}{c}\text { Glass/Epoxy } \\
{[0 / 90 / 90 / 0]_{3 s}}\end{array}$} & D2 & 2.74 & $300-400$ & Fiber failure \\
\cline { 2 - 5 } & D3 & 70.77 & $210-270$ & Fiber-Matrix interfacial debonding \\
\cline { 2 - 5 } & D4 & 5.79 & $168-190$ & Delamination \\
\hline
\end{tabular}

Table 1: Summary of failure mode characterization using DWT analysis of AE signals 


\section{Figure Captions:}

Fig 1: Specimen under flexural loading with AE sensors

Fig 2: AE time vs. load, AE Hits, Normalized AE counts rate and cumulative counts for hemp/epoxy laminates.

Fig 3: AE time Vs load, AE Hits, Normalized AE counts rate and cumulative counts for glass/epoxy laminates.

Fig 4: Decomposition of AE signals for hemp/epoxy laminates.

Fig 5: Frequency content of decomposed components for hemp/epoxy laminates.

Fig 6.Decomposition of AE signals for glass/epoxy laminates.

Fig 7: Frequency content of decomposed components for glass/epoxy laminates.

Fig 8: Level of decomposition of AE signals Vs Energy rate for each failure modes (a) damage initiation zone (b) Damage accumulation zone (c) Unstable damage zone and (d) Peak Frequency for hemp/epoxy laminates.

Fig 9: AE time Vs load, peak frequency and cumulative energy for hemp/epoxy laminates.

Fig 10: Level of decomposition of AE signals Vs Energy rate for each failure modes (a) damage initiation zone (b) Damage accumulation zone (c) Unstable damage zone and (d) Peak Frequency for glass/epoxy laminates.

Fig 11: AE time Vs load, peak frequency and cumulative energy for glass/epoxy laminates 


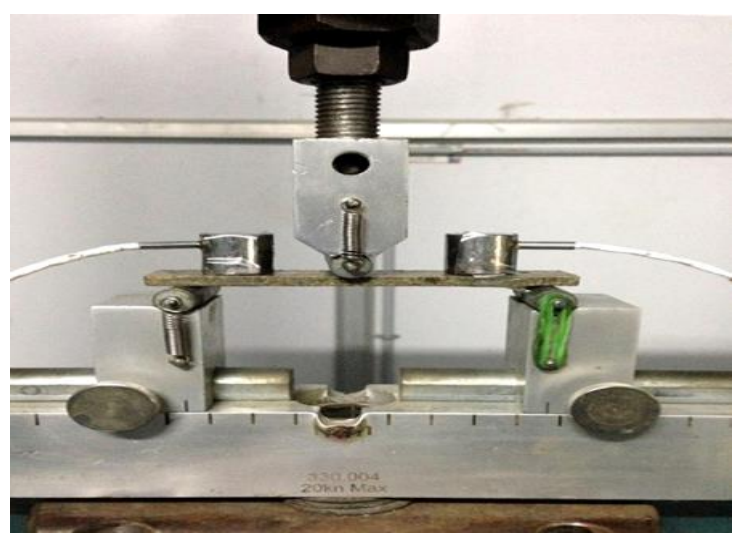

Fig 1: Specimen under flexural loading with AE sensors

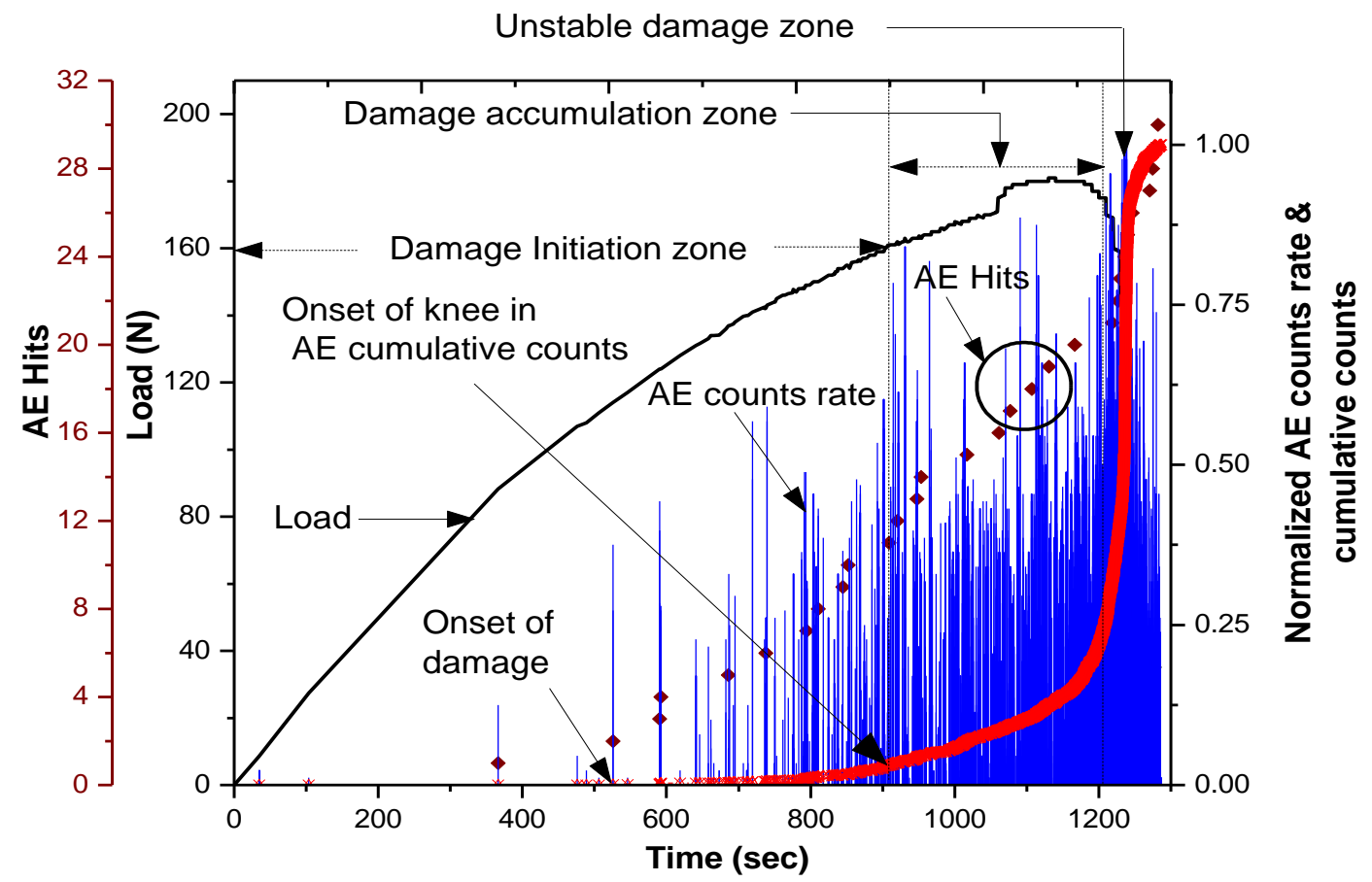


Fig 2: AE time vs. load, AE Hits, Normalized AE counts rate and cumulative counts for hemp/epoxy laminates.

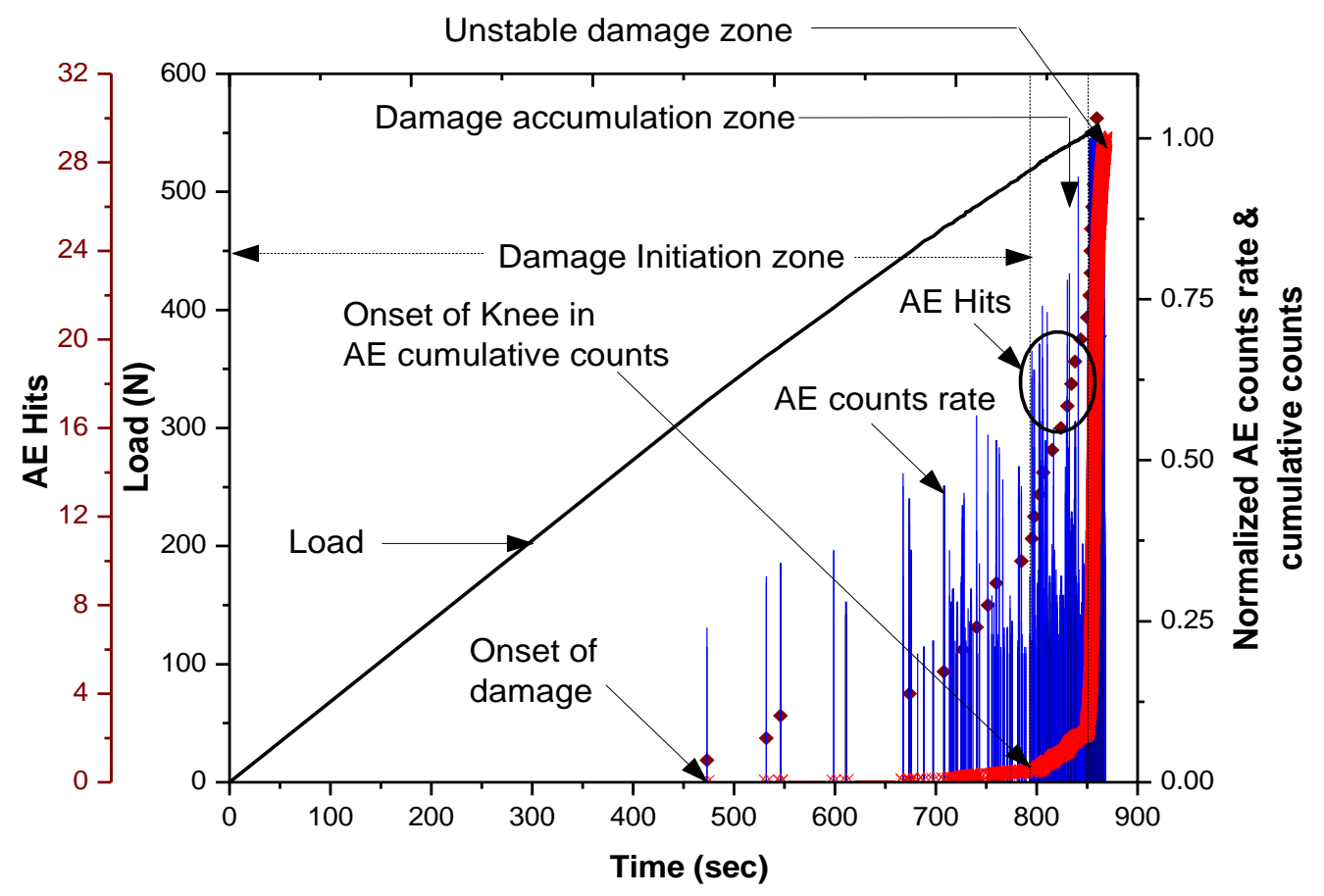

Fig 3: AE time Vs load, AE Hits, Normalized AE counts rate and cumulative counts for glass/epoxy laminates. 


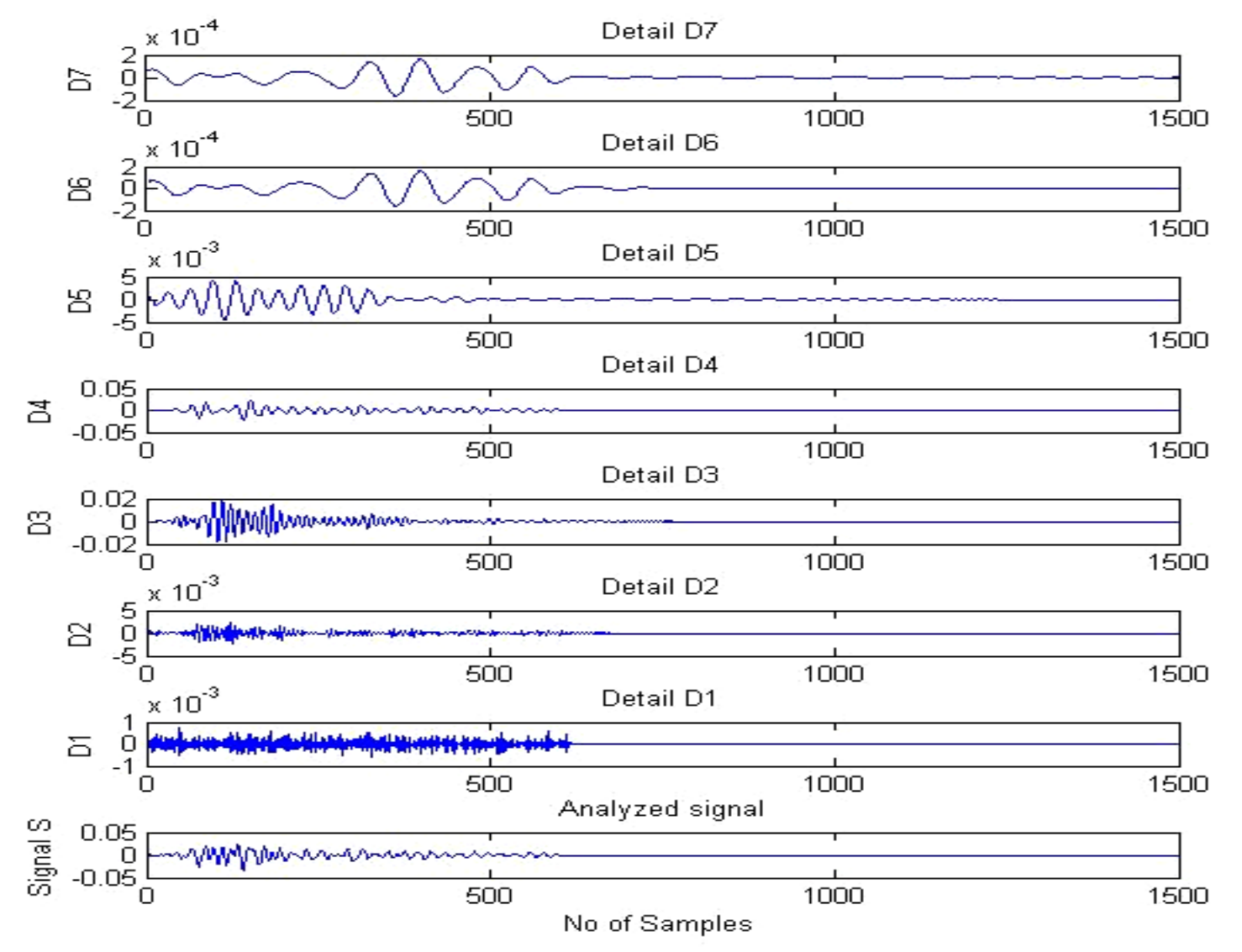

Fig 4: Decomposition of AE signals for hemp/epoxy laminates. 


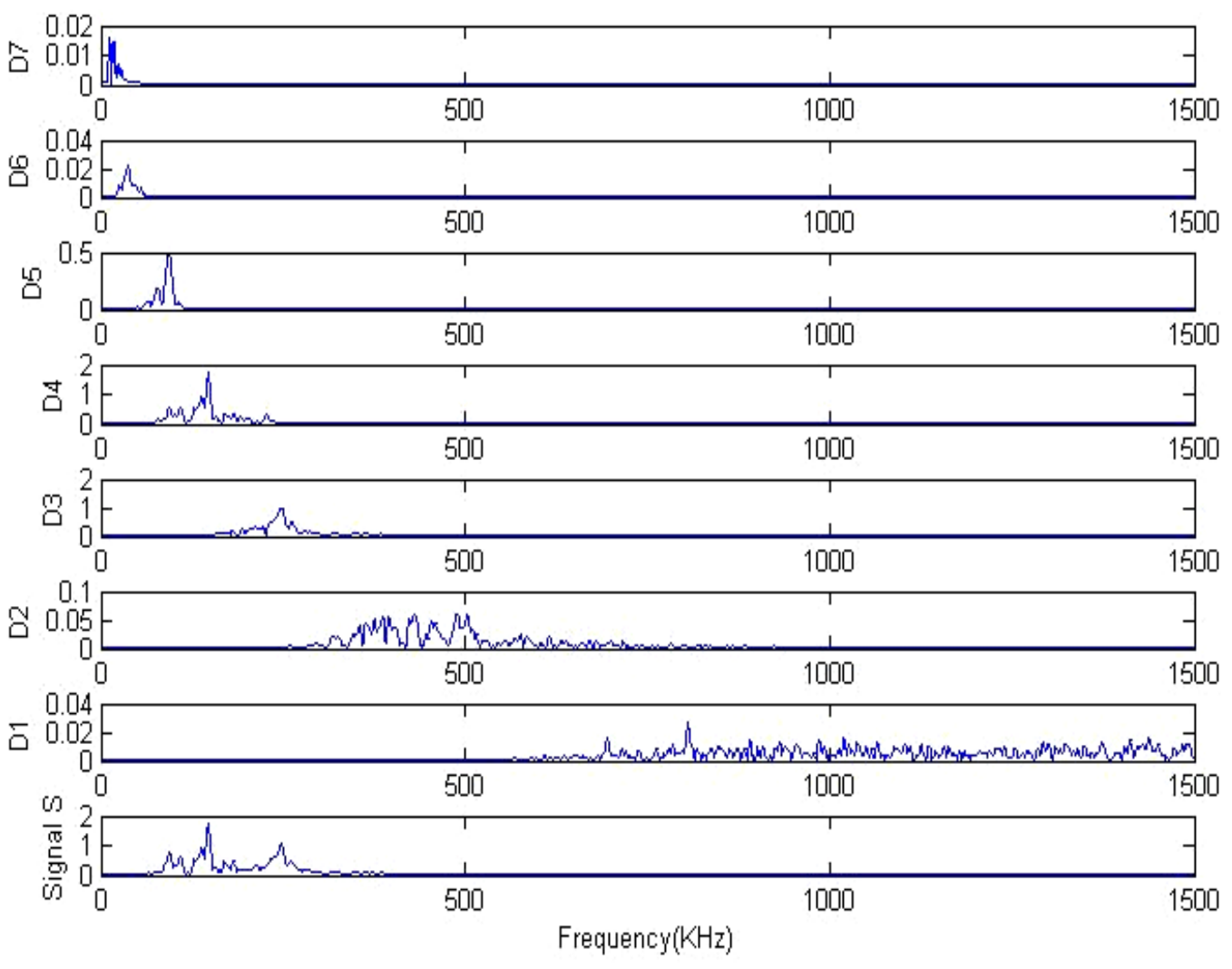

Fig 5: Frequency content of decomposed components for hemp/epoxy laminates 


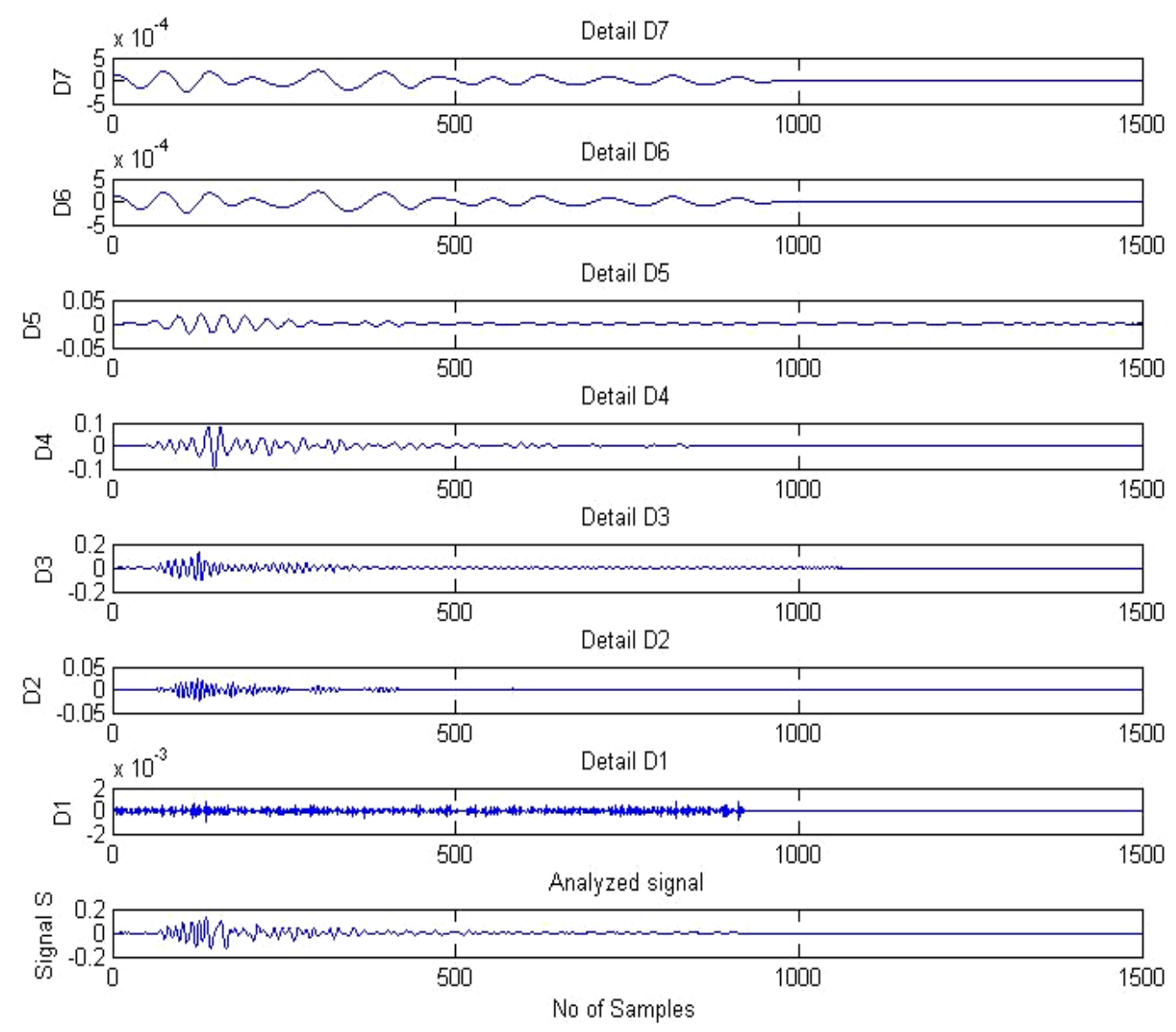

Fig 6.Decomposition of AE signals for glass/epoxy laminates. 

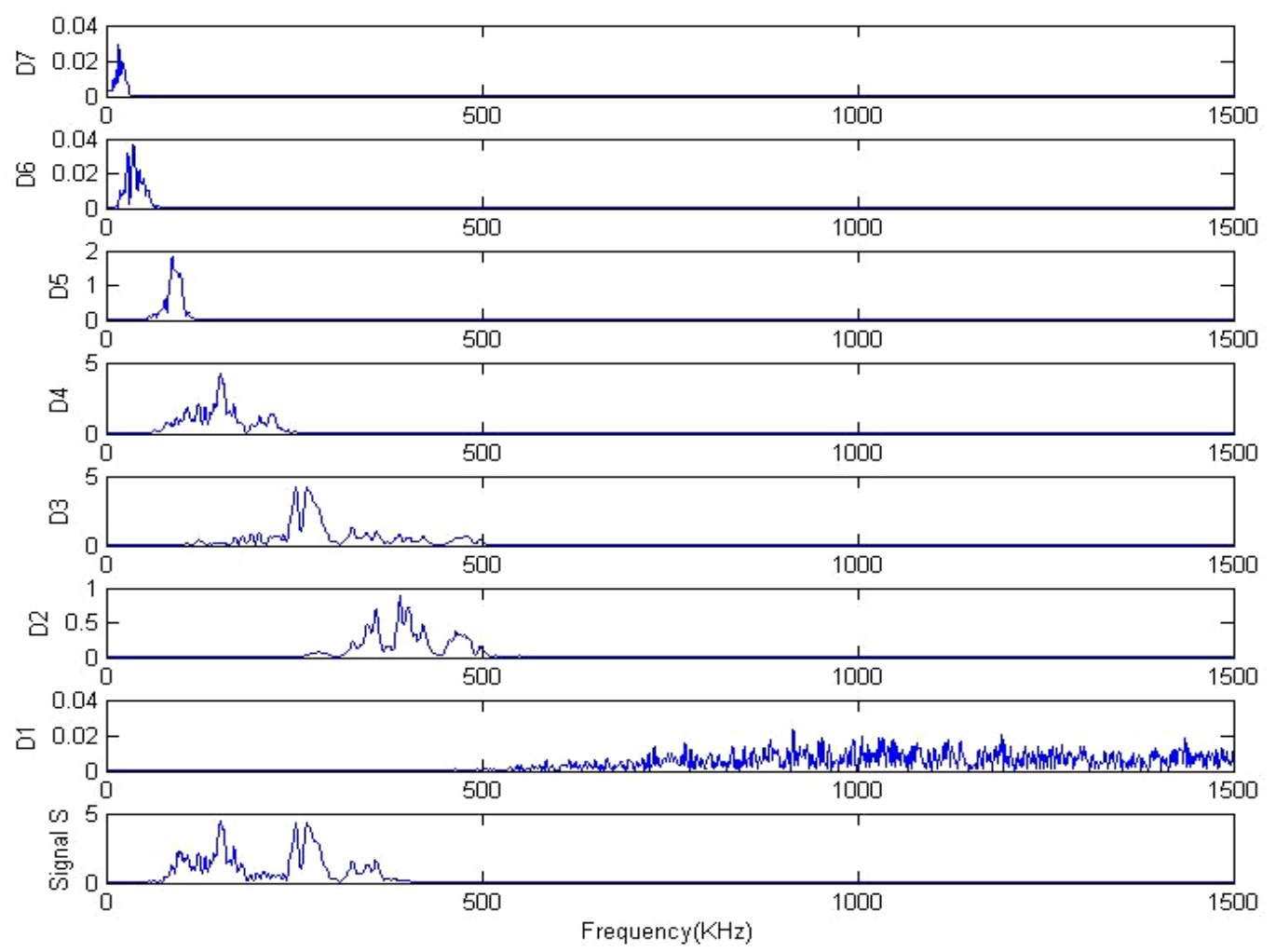

Fig 7: Frequency content of decomposed components for glass/epoxy laminates.
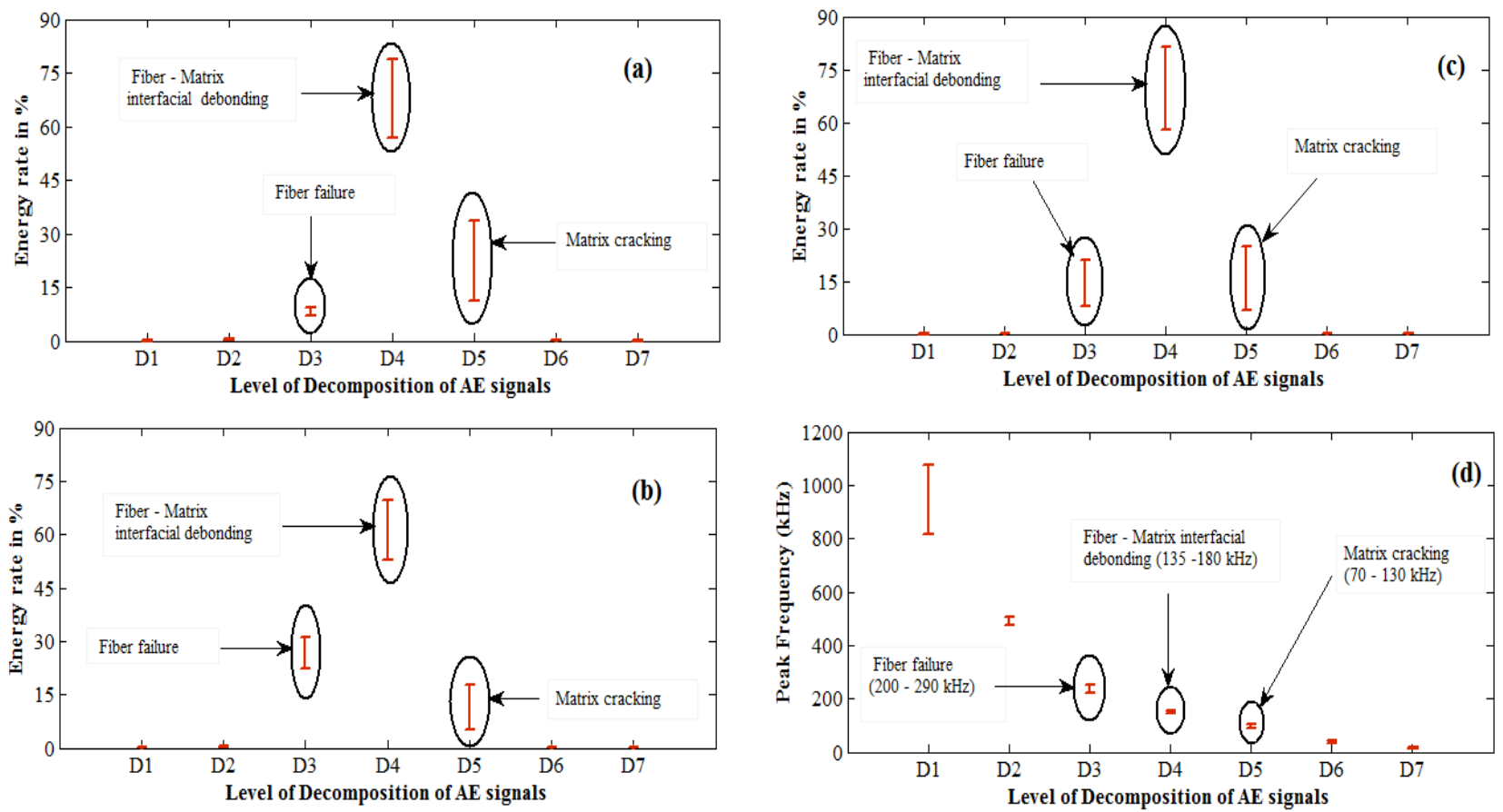

Fig 8: Level of decomposition of AE signals Vs Energy rate for each failure modes (a) damage initiation zone (b) Damage accumulation zone (c) Unstable damage zone and (d) Peak Frequency for hemp/epoxy laminates. 


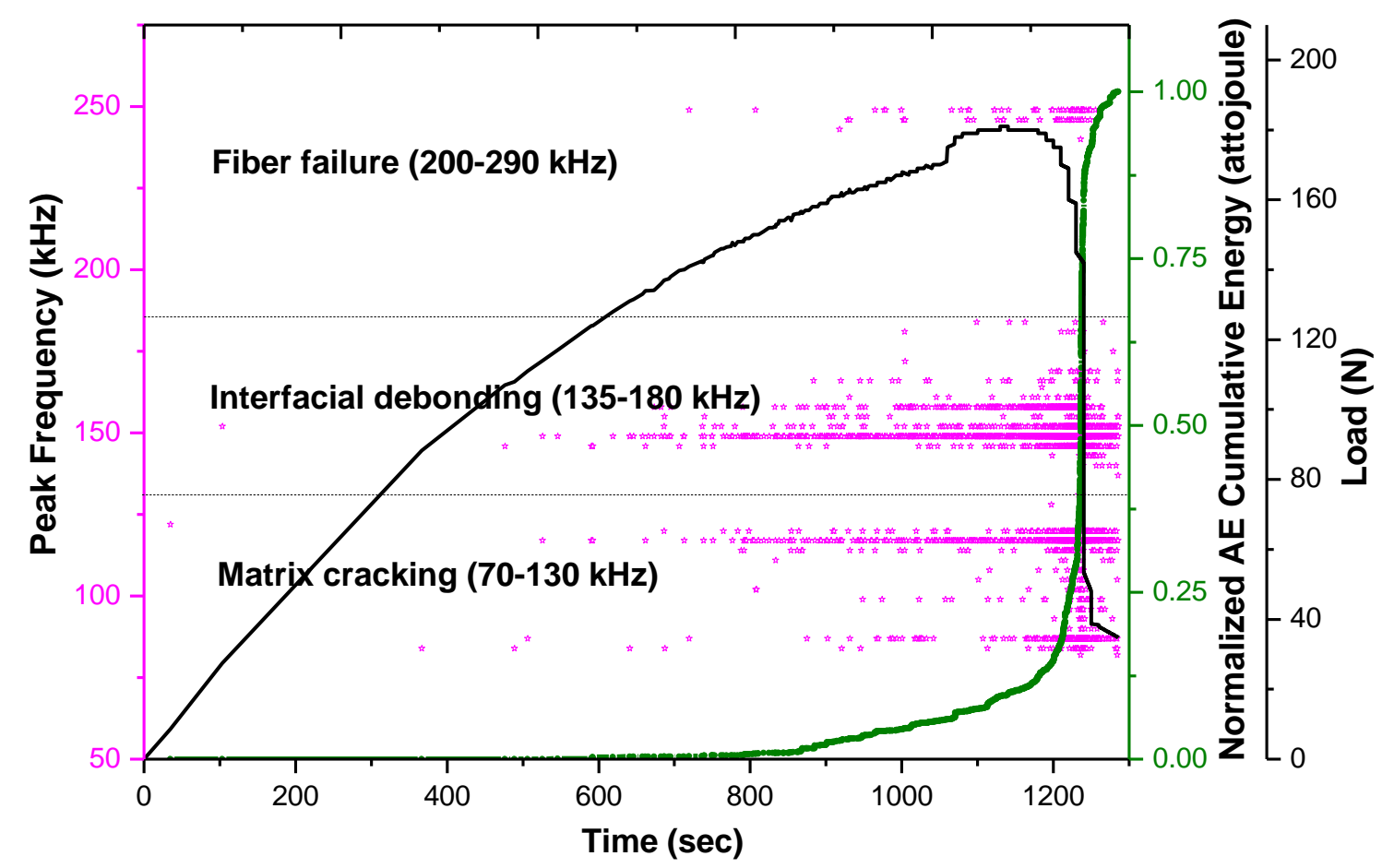

Fig 9: AE time Vs load, peak frequency and cumulative energy for hemp/epoxy laminates.
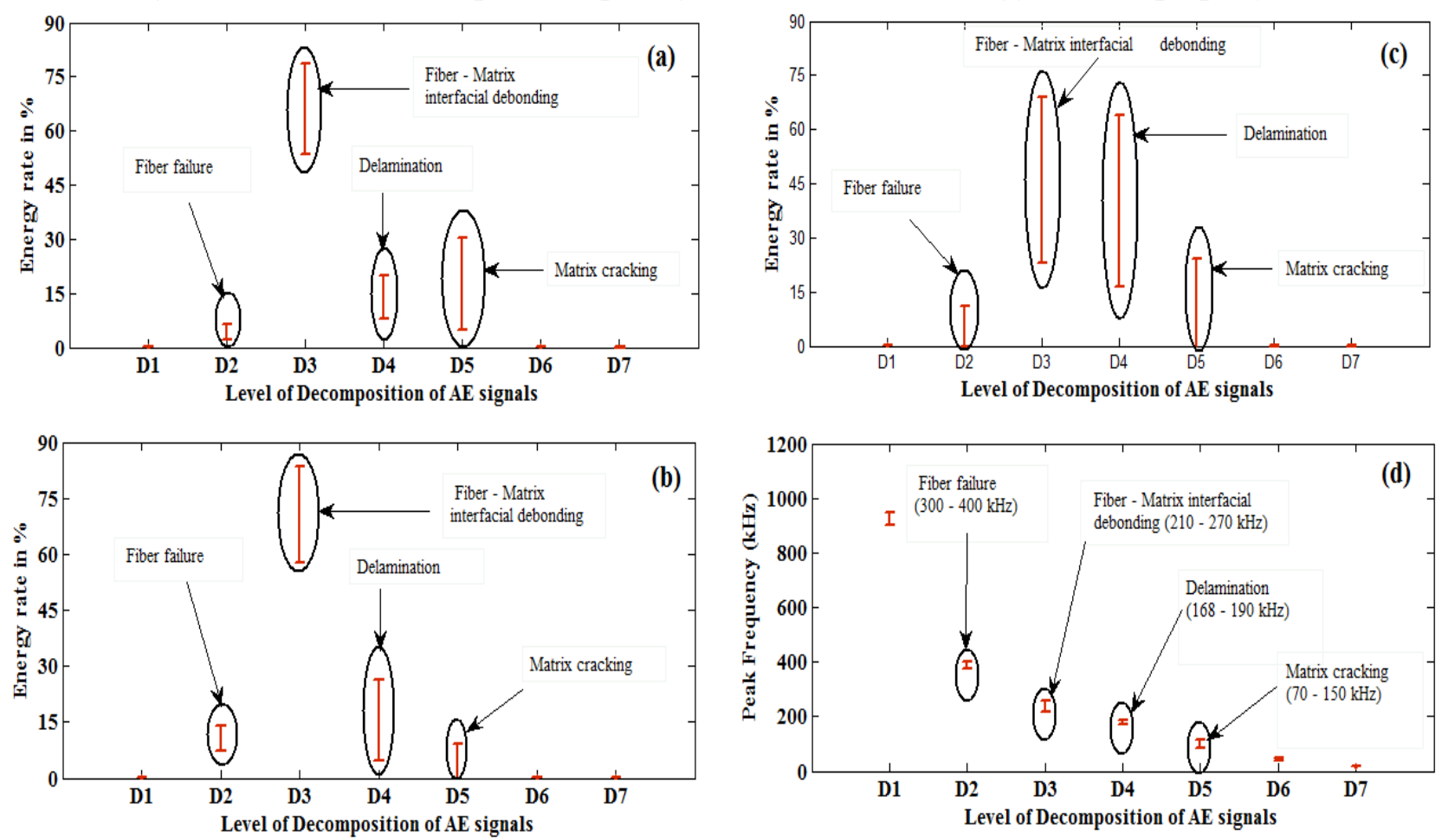
Fig 10: Level of decomposition of AE signals Vs Energy rate for each failure modes (a) damage initiation zone (b) Damage accumulation zone (c) Unstable damage zone and (d) Peak Frequency for glass/epoxy laminates.

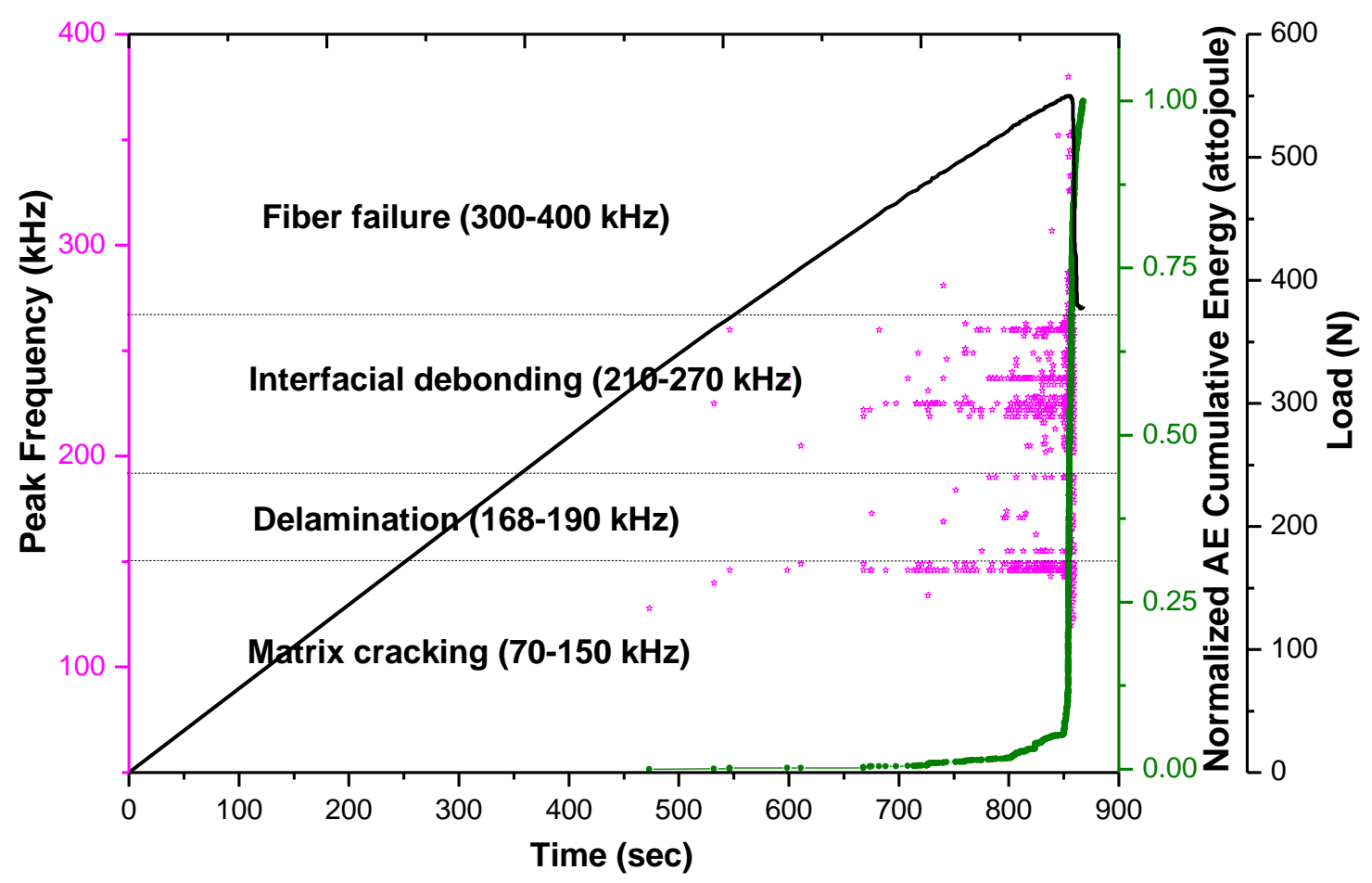

Fig 11: AE time Vs load, peak frequency and cumulative energy for glass/epoxy laminates 
